\title{
The fatty acid composition of Estonian and Latvian retail milk; implications for human nutrition compared with a designer milk
}

Article

Accepted Version

Henno, M., Ariko, T., Kaart, T., Kuusik, S., Ling, K., Kass, M., Jaakson, H., Leming, R., Givens, D. I., Sterna, V. and Ots, M. (2018) The fatty acid composition of Estonian and Latvian retail milk; implications for human nutrition compared with a designer milk. Journal of Dairy Research, 85 (2). pp. 247-250. ISSN 0022-0299 doi:

https://doi.org/10.1017/S0022029918000183 Available at https://centaur.reading.ac.uk/76979/

It is advisable to refer to the publisher's version if you intend to cite from the work. See Guidance on citing.

To link to this article DOI: http://dx.doi.org/10.1017/S0022029918000183

Publisher: Cambridge University Press

All outputs in CentAUR are protected by Intellectual Property Rights law, including copyright law. Copyright and IPR is retained by the creators or other copyright holders. Terms and conditions for use of this material are defined in the End User Agreement. 


\section{CentAUR}

Central Archive at the University of Reading

Reading's research outputs online 
1 The fatty acid composition of Estonian and Latvian retail milk; implications for human

2 nutrition compared with a designer milk

3

4 Merike Henno $^{1,2^{*}}$, Tiia Ariko ${ }^{2}$, Tanel Kaart ${ }^{1,2}$, Sirje Kuusik ${ }^{1,2}$, Katri Ling ${ }^{2}$, Marko Kass ${ }^{1,2}$,

5 Hanno Jaakson ${ }^{2}$, Ragnar Leming ${ }^{2}$, D. Ian Givens ${ }^{3}$, Vita Sterna ${ }^{4}$ and Meelis Ots ${ }^{1,2}$

6

$7 \quad{ }^{1}$ BioCC LLC, Tartu, Estonia

$8 \quad{ }^{2}$ Department of Animal Nutrition, Estonian University of Life Sciences, Tartu, Estonia

$9{ }^{3}$ Institute for Food, Nutrition and Health, University of Reading, United Kingdom

$10{ }^{4}$ Institute of Agricultural Resources and Economics, Latvia

*Correspondence: Merike Henno 


\section{Summary}

The study reported in this Research Communication compared retail milks' FA profiles from two neighbouring countries, estimated the potential contributions of these milks and a designer milk (achieved by changing the diet of the dairy cow) to the recommended human dietary intake of FA, and predicted (based on the milk FA profile) methane emission from dairy cows. Retail milk in Estonia and Latvia was purchased from supermarkets monthly for one year. To compare the FA composition of retail milk with designer milk with an increased PUFA content, the bulk milk FA profile from a separate field trial was used. Milk FA concentrations of two neighbouring countries were affected by state, season, and their interaction, while the main influence on all these factors were different feeding practices (grazing availability, forage to concentrate ratio and legume-rich silages vs. maize silages). Three cups (600 ml; fat content $2.5 \mathrm{~g} / 100 \mathrm{~g}$ ) of Estonian, or Latvian retail milk or designer milk per day contributed more to the recommended intakes of saturated FA (SFA) $(42.5 \%, 42 \cdot 7 \%, 38.7 \%$, respectively) than other FA. Compared to the retail milks, $\alpha$-linolenic acid estimated intake was almost doubled by designer milk consumption (19.7\% of adequate intake) without influencing summed intakes of SFA and trans FA. There were state and seasonal differences in the predicted methane outputs of dairy cattle based on retail milk FA. Although the FA profiles of retail milks in the two neighbouring countries were affected by state and season, an appreciable increase in human dietary intakes of beneficial fatty acids from milk, and concomitant reduction in methane emissions from dairy cows, can be achieved only by targeted feeding.

Keywords: Milk, retail milk, milk fatty acids, dietary intake.

Milk and dairy products are important sources of fat and fatty acids (FA) in the human diet. When choosing healthier eating patterns, it is recommended to reduce the intake of SFA and 
TFA, and to increase the consumption of polyunsaturated fatty acids (PUFA) (EFSA, 2010; USHHS and USDA, 2010). It is well established that the diet of dairy cows, and their genetic variation, are the main factors influencing milk FA composition (Shingfield et al., 2013). Altering the diet of dairy cows offers the opportunity to reduce milk medium-chain and total SFA content, and increase C18:1 cis-9, total PUFA and conjugated linoleic acid (CLA) contents in milk, although to a variable extent.

Milk production is often considered to have a substantial environmental impact due to methane $\left(\mathrm{CH}_{4}\right)$ emissions by cattle as a result of rumen fermentation. The moderate relationship between milk FA profile and $\mathrm{CH}_{4}$ emissions (van Lingen et al., 2014), both influenced by feeding of dairy cows, indicates that the FA profile of retail milk could be used as a non-invasive method to estimate $\mathrm{CH}_{4}$ production in dairy cows.

The objectives of this study were, (i) to compare the detailed FA profiles of retail milks of two neighbouring EU countries (Estonia and Latvia) with similar climate conditions but with some differences in dairy cows' management and feeding practice, (ii) to compare how Estonian and Latvian milks, and milk with a modified FA profile ('designer' milk) achieved by targeted feeding of the dairy cow, are related to the recommended human dietary intakes of different FA and FA groups, and (iii) to assess $\mathrm{CH}_{4}$ emissions via prediction equations based on milk FA composition.

\section{Material and methods}

Retail milk collection and milk fatty acid analysis

Homogenised and pasteurised retail milk $(2.5 \mathrm{~g} / 100 \mathrm{~g}$ fat, 11 carton or bag) was purchased from supermarkets in Estonia (Tartu) and Latvia (Riga) once a month for one year (March 2011 
- February 2012). All seven brands from three processors (including supermarket own labels) on sale in Estonia (total sample $\mathrm{n}=84$ ) and six processors' brands in different regions in Latvia (70\% of the market; total $n=72)$ were included in the study. Samples were kept frozen $\left(-20^{\circ} \mathrm{C}\right)$ and analysed at the milk quality laboratory of the Estonian University of Life Sciences, Tartu, Estonia.

The milk samples were prepared and analysed for FA profiles as described by Meremäe et al. (2012). Results for all FA were expressed as $\mathrm{g} / 100 \mathrm{~g}$ of total FA. Estimated contributions (\%) of recommended daily milk consumption to the recommended or adequate intakes of FA were calculated.

\section{Designer milk production and sampling}

In a trial (April - May, 2007) on a dairy farm in Estonia (300 Estonian Holstein dairy cows, loose housed, milked twice per day, average milk yield $26.8 \mathrm{~kg}$ per cow per day) cows were fed a total mixed ration (TMR) ad libitum in three feeding groups based on days in milk (DIM): 1-100, 101-250 and 251 up to end of the lactation. The TMR for all feeding groups contained grass-clover (50:50) silage, barley and maize meal, heat treated rapeseed cake (crude fat 100 g/kg DM), cold-pressed linseed cake (crude fat $200 \mathrm{~g} / \mathrm{kg} \mathrm{DM}$ ) and a mineral-vitamin mixture. Concentrate to forage ratio, metabolisable energy, crude protein and crude fat contents in DM in the three diets were respectively $59: 41,50: 50,34: 66 ; 11 \cdot 8 \mathrm{MJ} / \mathrm{kg}, 11 \cdot 2 \mathrm{MJ} / \mathrm{kg}, 10 \cdot 5 \mathrm{MJ} / \mathrm{kg}$; $169 \mathrm{~g} / \mathrm{kg}, 156 \mathrm{~g} / \mathrm{kg}, 147 \mathrm{~g} / \mathrm{kg}$ and $57.7 \mathrm{~g} / \mathrm{kg}, 45.4 \mathrm{~g} / \mathrm{kg}, 41.6 \mathrm{~g} / \mathrm{kg}$. The mean FA profile of four bulk milk samples collected was used for the comparison.

\section{Prediction of methane production}


The equation of Van Lingen et al. (2014) was used for $\mathrm{CH}_{4}$ prediction $\left(\mathrm{CH}_{4}(\mathrm{~g} / \mathrm{kg}\right.$ of $\mathrm{FPCM}$, fat-protein corrected milk) $=21.13-1.38 \times \mathrm{C} 4: 0+8.53 \times \mathrm{C} 16: 0$-iso $-0.22 \times$ cis-9 C18:1 $0 \cdot 59 \times$ trans-10+11 C18:1; $\left.\mathrm{R}^{2}=0 \cdot 47\right)$. All FA in the equation were as $\mathrm{g} / 100 \mathrm{~g}$ FA.

\section{Statistical analysis}

The effects of country, season (summer $=$ May - Oct. $v s$ winter $=$ Nov. - April $)$ and country by season interaction on the FA composition of retail milks and predicted $\mathrm{CH}_{4}$ emissions were tested using fixed effect analysis of variance (ANOVA) including also the random effect of milk product brand (to consider any potential correlation between milk samples of the same brand) and two replicate measures of the same sample as repeated measures. The denominator degrees of freedom in ANOVA were calculated according to the Kenward-Roger method. To identify common patterns in milk FA profiles, and analyse their differences, principal component analysis (PCA) was performed. Additionally the FA compositions, predicted $\mathrm{CH}_{4}$ emissions and estimated contributions (\%) of recommended daily milk consumption to the recommended or adequate intakes of FA were compared between Estonian and Latvian retail milks and designer milk using the t-tests with degrees of freedom equal to number of samples and followed by Bonferroni correction for multiple testing. The modelling was carried out using SAS 9.4 procedure MIXED and PCA with R 3.2.3 package ade4. The results were considered statistically significant at $P \leq 0.05$.

\section{Results and discussion}

\section{The fatty acid composition of retail milks}


Even though Estonia and Latvia are neighbouring countries with similar landscape and climate,

farming systems and feeding practices are different with grazing availability (16\% and 60\% of herds, respectively), forage to concentrate ratio (F:C) (55:45 and 70:30, respectively), use of legume-rich forage (40\% of silages) and a lower proportion of maize silages in Estonia (5\% vs $19 \%$ in Latvia). These differences were reflected in the FA composition of retail milks. The FA concentrations of most milk FA, as well as FA groups, were affected by state and season, and many by the interaction of state and season (online Supplementary Table S1). The effect of season on the FA composition of retail milk was more pronounced than the effect of state.

Results of PCA of the whole dataset are presented in online Supplementary Fig. S1, and the patterns of FA concentrations described by the first and the second PC according to state, season and state by season in Fig. 1 .

\section{(Figures 1 near here)}

Relative to the overall FA pattern of Estonian retail milk, the FA pattern of Latvian retail milk was shifted towards a positive correlation with PC1 (Fig. 1A), which was related to the higher proportions of ruminal biohydrogenation intermediates including C18:1 trans-11, CLA and branched-chain FA (BCFA) originating from rumen microbes. The overall summer milk FA pattern was shifted towards the first and the second (C18:0, most of ruminal biohydrogenation intermediates, CLA and majority of the n-3 FA, n-6 FA) quarters (Q) of the plot (Fig. 1B). The same distinctive feature was present in both Estonian and Latvian summer milk reflecting the higher dietary supply of PUFA, especially that of C18:3 n-3, from fresh grass compared to winter diets (Dewhurst et al., 2006). Compared to Estonian summer milk, the FA pattern of Latvian summer milk was shifted towards the first and fourth (BCFA, C15:0 and C17:0) quarters of the plot (Fig. 1C). Regarding winter milk, the FA pattern of Latvian winter milk was shifted towards the higher proportions of BCFA, C15:0 and C17:0 (IVQ) compared to Estonian winter milk and lower proportions of de novo synthesised FA (IIIQ) also FA clustered in the 
second quarter (Fig. 1C). The higher concentrations of BCFA and linear odd-chain FA (C15:0, C17:0) in Latvian winter milk are in line with a previously reported (Vlaeminck et al., 2006) effect of higher $\mathrm{F}: \mathrm{C}$ ratio increasing the proportions of bacteria-derived $\mathrm{FA}$ leaving the rumen.

\section{Human consumption of health-related fatty acids}

The estimated contribution of Estonian and Latvian retail milk to the recommended or adequate intakes of FA for adults (Table 1) confirmed previous suggestions (Shingfield et al., 2013) that milk fat is an important source for SFA ( $43 \%$ of the recommended upper limit) if the recommended amount $(600 \mathrm{~mL}$, fat content $2.5 \mathrm{~g} / 100 \mathrm{~g}$; Tervise Arengu Instituut, 2017) is consumed. Estimated contributions for desirable $\alpha$-linolenic acid (ALA; C18:3 n-3) were relatively low but still provided above $8 \%$ of adequate intake ( $1 \cdot 1 \mathrm{~g}$ or $0.5 \%$ of energy intake). Regarding the sum of long-chain n-3 PUFA (eicosapentaenoic acid (EPA; C20:5 n-3) and, docosahexaenoic acid (DHA; C22:6 n-3), the latter was not detected in this study, but estimated intake of long-chain n-3 PUFA was enhanced ( 3.5\% vs $\sim 9.0 \%$ of $250 \mathrm{mg}$, Table 1) by docosapentaenoic acid (DPA; C22:5 n-3), the concentration of which was greater than EPA (online Supplementary Table S1). The function of dietary DPA remains uncertain, although some reports indicate it may be beneficial to health (Howe et al., 2007)

In line with the results of feeding trial with dairy cow diet supplemented with linseed (Stergiadis et al., 2014) the FA profile of designer milk differed substantially from retail milk profiles (Fig. 1). Our designer milk contained more ALA, long-chain n-3 FA, trans FA and less SFA compared with retail milks (online Supplementary Table S1). Designer milk consumption would increase the estimated intake of C18:3 n-3, $\Sigma$ n-3 and sum of essential FA [ALA+linoleic acid (LA; C18:2 n-6)] but also EPA and DPA (Table 1). The estimated contribution of milk fat to the recommended upper limit for dietary intake of SFA was lower for designer milk compared with retail milk, and it was also lower for designer milk for SFA+TFA. 
173 Even though the effect of the state on the FA composition of retail milk was observed for most 174 FA, only small differences were observed in estimated consumption of discussed FA and FA 175 groups at the recommended milk intake level of $600 \mathrm{~mL} / \mathrm{d}$. However, while consuming designer 176 milk ALA intake would be almost doubled to $19.7 \%$ of AI.

Predicted $\mathrm{CH}_{4}$ emissions in dairy cows

Although van Lingen et al. (2014) indicated that milk FA composition has only a moderate potential for $\mathrm{CH}_{4}$ prediction per unit of milk, the method still enables to roughly assess regional

181 differences, modify feeding strategies and mitigate $\mathrm{CH}_{4}$ emissions. Despite the dissimilarities in feeding strategies, there were no differences in yearly mean $\mathrm{CH}_{4}$ output values from dairy cows $(\mathrm{g} / \mathrm{kg}$ FPCM; $P=0 \cdot 51)$ between the two states. The predicted $\mathrm{CH}_{4}$ emissions were higher $(P<0.001)$ during the winter period compared to the summer 12.19 vs 11.92 and 12.62 vs 11.65 in Estonia and Latvia, respectively. Our simulation showed notably lower enteric $\mathrm{CH}_{4}$ emissions when producing designer milk (11.06; $P<0.001)$ compared to conventional production (12.06 for Estonia and 12.11 for Latvia). Lower predicted $\mathrm{CH}_{4}$ emission while producing designer milk, caused by feeding oilseed (Meale et al., 2013), shows that production of favourable for human health designer milk with higher PUFA content has also environmental advantages.

The research was financed by EU Regional Development Fund in the framework of the Competence Centre Program of Estonia under Projects EU30002 and EU 48686 of BioCC LLC; institutional research funding of Estonian Research Council, project IUT8-1. 


\section{References}

Dewhurst RJ, Shingfield KJ, Lee MRF \& Scollan ND 2006 Increasing the concentrations of beneficial polyunsaturated fatty acids in milk produced by dairy cow in high-forage systems. Animal Feed Science and Technology 131 168-206

EFSA (European Food Safety Authority) 2010 Scientific opinion on dietary values for fats, including saturated fatty acids, polyunsaturated fatty acids, monounsaturated fatty acids, trans fatty acids, and cholesterol. EFSA Journal 8 1-107

Howe P, Buckley J \& Meyer B 2007 Long-chain omega-3 fatty acids in red meat. Nutrition \& Dietetics, 64 (Suppl 4) S135-S13

Meale SJ, McAllister TA, Beauchemin KA, Harstad OM \& Chaves AV 2013 Strategies to reduce greenhouse gases from livestock. Acta Agriculturae Scandinavica, Section AAnimal Science 62 199-211

Meremäe K, Roasto M, Kuusik S, Ots M \& Henno M 2012 Trans fatty acid contents in selected dietary fats in the Estonian market. Journal of Food Science 77 163-168

Nordic Council of Ministers 2014 Nordic Nutrition Recommendations 2012: Integrating nutrition and physical activity http://dx.doi.org/10.6027/Nord2014-002

Shingfield KJ, Bonnet M \& Scollan ND 2013 Recent developments in altering the fatty acid composition of ruminant-derived foods. Animal 7 132-162

Stergiadis S, Leifert C, Eyre CJ, Steinshamn H \& Butler G 2014 Improving the fatty acid profile of winter milk from housed cows with contrasting feeding regimes by oilseed supplementation. Food Chemistry 164 193-300

Tervise Arengu Instituut [National Institute for Health Development] 2017 Eesti toitumis- ja liikumissoovitused [Estonian nutrition and physical activity recommendations] 2015 
USHHS and USDA (U.S. Department of Health and Human Services and U.S. Department of Agriculture) 2015-2020 Dietary Guidelines for Americans. 8th Edition. December 2015. 2015-2020 Dietary Guidelines for Americans - health.gov

225 Van Lingen HJ, Crompton LA, Hendriks WH, Reynolds CK and Dijkstra J 2014 Meta-analysis of relationships between enteric methane yield and milk fatty acid profile in dairy cattle. Journal of Dairy Science 97 7115-7132

Vlaeminck B, Fievez V, Cabrian ARJ, Fonseca AJM \& Dewhurst RJ 2006 Factors affecting odd- and branched-chain fatty acids in milk: A review. Animal Feed Science and Technology 131 389-417 
Table 1. Estimated contribution (\%) of recommended daily consumption $(600 \mathrm{~mL}$, fat content $2.5 \mathrm{~g} / 100 \mathrm{~g}$ ) of Estonian and Latvian retail milk and designer milk, to the recommended or adequate intakes of FA for females with energy intake of $\sim 8.37 \mathrm{MJ} / \mathrm{d}$

\begin{tabular}{|c|c|c|c|c|}
\hline \multirow{2}{*}{ Fatty acid } & \multirow{2}{*}{$\begin{array}{l}\text { Recommendations, adequate } \\
\text { intake }\left(\mathrm{AI}^{\dagger}\right)\end{array}$} & \multicolumn{2}{|c|}{ Means of retail milk } & \multirow{2}{*}{$\begin{array}{l}\text { Designer } \\
\text { milk, \% }\end{array}$} \\
\hline & & Estonia, \% & Latvia, \% & \\
\hline SFA & $<10 \%$ of energy intake $e^{\ddagger},, \mathbb{I}$ & $42 \cdot 5^{\mathrm{a}}$ & $42 \cdot 7^{\mathrm{a}}$ & $38 \cdot 7^{b}$ \\
\hline $\mathrm{SFA}+\mathrm{TFA}$ & $\leq 10 \%$ of energy intake $e^{\dagger \dagger}$ & $45 \cdot 2^{\mathrm{a}}$ & $45 \cdot 6^{b}$ & $43 \cdot 4^{\mathrm{c}}$ \\
\hline cis PUFA & $5-10 \%$ of energy intake $e^{\S, \mathbb{I}}$ & $3 \cdot 62-1 \cdot 81$ & $3 \cdot 39-1 \cdot 69$ & $5 \cdot 53-2 \cdot 76$ \\
\hline cis MUFA & $10-20 \%$ of energy intake ${ }^{\S, \text { II }}$ & $15 \cdot 7-10 \cdot 4$ & $15 \cdot 2-10 \cdot 2$ & $16 \cdot 6-11 \cdot 1$ \\
\hline C18:3n-3 & AI: $1 \cdot 1 \mathrm{~g}^{\ddagger}$ & $8 \cdot 57^{\mathrm{a}}$ & $8 \cdot 70^{\mathrm{a}}$ & $19 \cdot 7^{b}$ \\
\hline C18:3 n-3 & AI: $0.5 \%$ of energy intake ${ }^{\S, ~}+\pi I$ & $8 \cdot 49^{\mathrm{a}}$ & $8 \cdot 62^{a}$ & $19 \cdot 5^{\mathrm{b}}$ \\
\hline C18:2 n-6 & AI: $11 \mathrm{~g}^{\ddagger}$ & $2 \cdot 14^{\mathrm{a}}$ & $1 \cdot 93^{b}$ & $2 \cdot 93^{\mathrm{c}}$ \\
\hline C18:2 n-6 & AI: $4 \%$ of energy intake & $2 \cdot 65^{\mathrm{a}}$ & $2 \cdot 39^{b}$ & $3 \cdot 62^{\mathrm{c}}$ \\
\hline $\mathrm{EPA}+\mathrm{DHA}$ & AI: $250 \mathrm{mg}^{\dagger+}$ & $3 \cdot 44^{\mathrm{a}}$ & $3 \cdot 59^{b}$ & $5 \cdot 03^{c}$ \\
\hline $\mathrm{EPA}+\mathrm{DHA}+\mathrm{DPA}$ & AI: $250 \mathrm{mg}^{\dagger \dagger}$ & $8 \cdot 81^{\mathrm{a}}$ & $8 \cdot 92^{\mathrm{a}}$ & $12 \cdot 2^{\mathrm{b}}$ \\
\hline$\Sigma \mathrm{n}-3$ & $\geq 1 \%$ of energy intake ${ }^{\S, \text { II }}$ & $5 \cdot 36^{\mathrm{a}}$ & $5 \cdot 44^{\mathrm{a}}$ & $11 \cdot 3^{\mathrm{b}}$ \\
\hline$n-3+n-6$ & $3 \%$ of energy intake $e^{\S}$ & $4 \cdot 94^{\mathrm{a}}$ & $4 \cdot 62^{b}$ & $8 \cdot 07^{\mathrm{c}}$ \\
\hline
\end{tabular}

${ }^{\dagger} \mathrm{AI}$, adequate intake.

$\$ 2015-2020$ Dietary Guidelines for Americans (USHHS and USDA, 2015).

${ }^{\S}$ Nordic Nutrition Recommendations 2012. Recommended intake of macronutrients

238 (excluding energy from alcohol) (Nordic Council of Ministers, 2014).

239 IEstonian nutrition and physical activity recommendations 2015 (Tervise Arengu Instituut, 240 2017).

$241{ }^{\dagger}$ Not used in cited recommendations. 
$242 \$$ Scientific opinion on dietary values for fats, including saturated fatty acids, polyunsaturated 243 fatty acids, monounsaturated fatty acids, trans fatty acids, and cholesterol (EFSA, 2010).

$244 \quad{ }^{a, b, c}$ Means with different superscript letters are statistically significantly different $(P<0 \cdot 05, t-$ 245 tests with degrees of freedom equal to number of samples and followed by Bonferroni 246 correction for multiple testing). 
247 Figure legend:

248

249 Fig. 1:

250 The patterns of FA concentrations described by the first and the second principal component:

251 (A) fatty acid patterns by national state, (B) fatty acid patterns by season, (C) fatty acid patterns

252 by national state and season. In all figures, also the location of designer milk samples is

253 presented. The factor loadings showing the relative importance of fatty acids in first two 254 principal components are presented in Supplementary Figure S1. 
$255 \quad$ Fig. 1

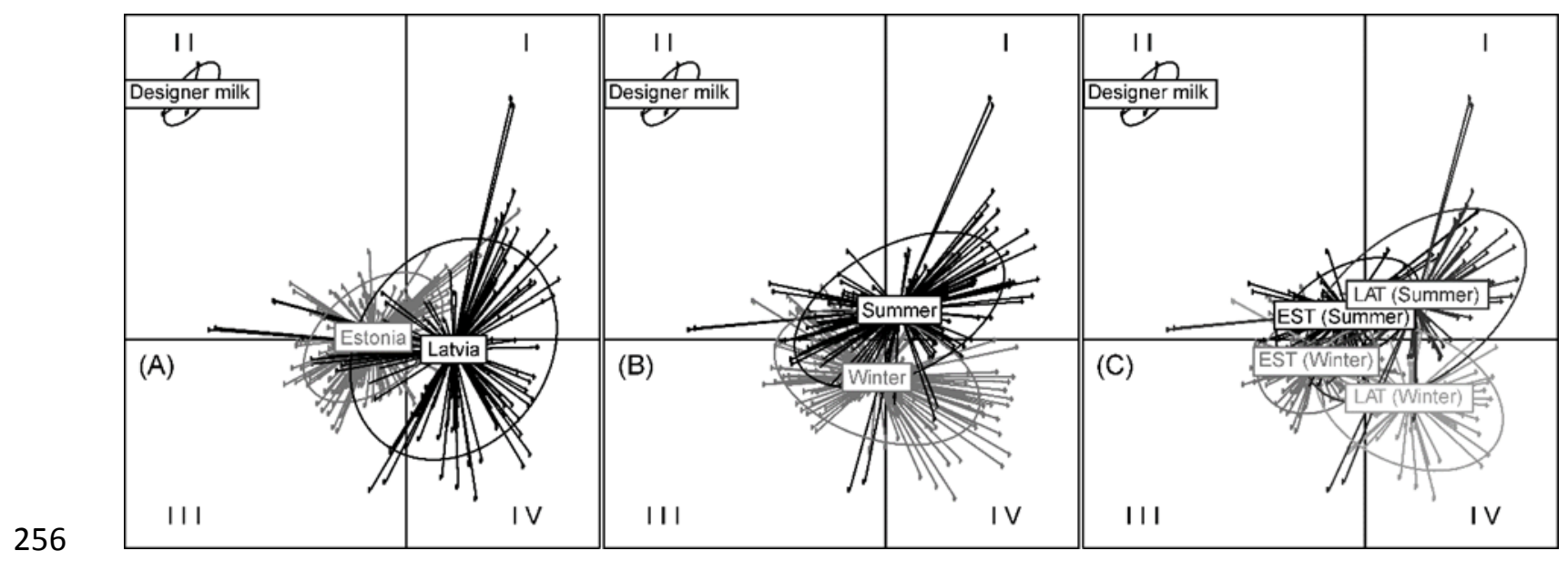

